\title{
Perceived Stress in Epilepsy: A Comparative Study across Patients, Their Siblings and Normal Controls
}

\author{
Ashish K Yadav ${ }^{1}$, Mohit Shukla ${ }^{2}$, Narendra K Singh ${ }^{3}$, Nishant Goyal ${ }^{4}$
}

\begin{abstract}
Background: Epilepsy is a common childhood neurological disorder with complex symptoms. Family members, especially parents and siblings, experience emotional pain, especially when seizures occur frequently. Stress can be defined as the psychological and physical response of the caregiver as they try to cope with the challenges of caring for their sick child. Therefore to maintain this domain this study is designed to assess the stress of a patient with epilepsy (PWE) and their siblings.

Objective: To examine the perceived stress of persons with epilepsy, their siblings and normal controls.

Method: This study was a part of a cross-sectional, hospital-based study and the samples were selected through the purposive sampling process. In the study, 60 people were included (20 patients diagnosed with epilepsy according to the International League against Epilepsy (ILAE), 20 siblings of patients with epilepsy, and 20 people with general control). The age range was $20-45$ in each group. Age, education, and family income have been compared between siblings and general controls. The perceived stress scale was used for all participants in the stress assessment. For the siblings and normal controls, GHQ-12 was applied and a person who scored less than three in GHQ-12 was included in the study.

Result and conclusion: Findings of the present study concluded that patient and their siblings had higher stress in comparison to normal individuals.
\end{abstract}

Keywords: Epilepsy, Quality of life, Siblings.

Eastern Journal of Psychiatry (2020): 10.5005/jp-journals-11001-0007

\section{INTRODUCTION}

Epilepsy is a common medical and social problem or group of problems with different characteristics. Epilepsy is often described as a recurring episode. The word "epilepsy" is derived from the Latin and Greek words for "seizure" or "to seize upon." This means that epilepsy is an old disease. Epilepsy is still being spread in an astonishing way around the world. There are no racial, regional, or social boundaries. It occurs in both men and women, all ages, especially in childhood, adolescence, and adulthood. ${ }^{1}$ Epilepsy is a common, sometimes incurable, physical injury with psychological and economic consequences that affect the quality of life. ${ }^{2}$ Perceived stress is one of the most frequently reported seizures in people with epilepsy (PWE). According to a previous study, up to $82 \%$ of PWEs identified significant stress as a seizure traps. ${ }^{3}$ The stress experienced by PWE may be associated with their low quality of life. Therefore, we compared the degree of perceived stress in patients, their siblings and normal individuals.

\section{Materials and Methods}

\section{Design}

This study was a cross-sectional one and aimed to examine the perceived stress of persons with epilepsy their siblings and normal controls. The study was conducted in the outpatient department at the Center for Cognitive Neurosciences, Central Institute of Psychiatry, Kanke, Ranchi, Jharkhand, India. Research samples were recruited in the form of purposive sampling. The samples consisted 20 patients diagnosed with epilepsy as per ILAE criteria, 20 siblings of patients with Epilepsy and 20 normal control individuals.

\footnotetext{
1,3 Department of Psychiatric Social Work, Central Institute of Psychiatry, Kanke, Ranchi, Jharkhand, India

${ }^{2}$ Department of Psychiatry, Dr. Ram Manohar Lohia Hospital, New Delhi, India

${ }^{4}$ Department of Psychiatry, Central Institute of Psychiatry, Kanke, Ranchi, Jharkhand, India

Corresponding Author: Mohit Shulka, Department of Psychiatry, Dr. Ram Manohar Lohia Hospital, New Delhi, India, e-mail: mohit.shukla102@gmail.com

How to cite this article: Yadav AK, Shukla M, Singh NK, et al. Perceived Stress in Epilepsy: A Comparative Study across Patients, Their Siblings and Normal Controls. East J Psychiatry 2020;23(1):12-14.

Source of support: Nil

Conflict of interest: None
}

Age, education and family income will be matched between siblings \& normal controls.

\section{Participants}

The samples included 20 patients diagnosed with Epilepsy as per ILAE criteria, 20 siblings of patients with epilepsy and 20 normal control individuals.

\section{Procedure}

Patients with epilepsy, their siblings, and the normal individuals were informed for the purpose of the study after written consent was obtained for data instruments specially designed socio-demographic data sheet, Perceived Stress Scale were applied to all participants and

() The Author(s). 2020 Open Access This article is distributed under the terms of the Creative Commons Attribution 4.0 International License (https://creativecommons. org/licenses/by-nc/4.0/), which permits unrestricted use, distribution, and non-commercial reproduction in any medium, provided you give appropriate credit to the original author(s) and the source, provide a link to the Creative Commons license, and indicate if changes were made. The Creative Commons Public Domain Dedication waiver (http://creativecommons.org/publicdomain/zero/1.0/) applies to the data made available in this article, unless otherwise stated. 
Perceived Stress in Epilepsy

Table 1: Sociodemographic profile of the sample population $(N=60)$ : Categorical variables

\begin{tabular}{|c|c|c|c|c|c|c|c|}
\hline \multirow[b]{2}{*}{ S.No } & \multirow{2}{*}{\multicolumn{2}{|c|}{ Variable }} & \multicolumn{3}{|c|}{ No $(n)$} & \multirow[b]{2}{*}{$x^{2}$} & \multirow[b]{2}{*}{$p$} \\
\hline & & & Patients & Siblings & Control & & \\
\hline \multirow{2}{*}{1} & \multirow{2}{*}{ Sex } & Male & 11 & 12 & 13 & \multirow{2}{*}{0.417} & \multirow{2}{*}{0.812} \\
\hline & & Female & 9 & 8 & 7 & & \\
\hline \multirow{2}{*}{2} & \multirow{2}{*}{ Types of family } & Joint & 16 & - & 15 & \multirow{2}{*}{0.285} & \multirow{2}{*}{0.906} \\
\hline & & Nuclear & 4 & & 5 & & \\
\hline \multirow{2}{*}{3} & \multirow{2}{*}{ Occupation } & Employed & 15 & 10 & 13 & \multirow{2}{*}{4.227} & \multirow{2}{*}{0.376} \\
\hline & & Unemployed & 5 & 10 & 7 & & \\
\hline \multirow{2}{*}{4} & \multirow{2}{*}{ Domicile } & Rural & 14 & - & 16 & \multirow{2}{*}{2.427} & \multirow{2}{*}{0.673} \\
\hline & & Urban & 7 & - & 4 & & \\
\hline \multirow{2}{*}{5} & \multirow{2}{*}{ Religion } & Hindu & 17 & - & 18 & \multirow{2}{*}{0.683} & \multirow{2}{*}{0.832} \\
\hline & & Muslim & 3 & - & 2 & & \\
\hline
\end{tabular}

Table 2: Clinical profile of the sample population $(N=20)$

\begin{tabular}{llll}
\hline S.No & \multicolumn{1}{c}{ Variable } & Mean & SD \\
\hline 1 & Age of onset (years) & 21.25 & 7.47 \\
2 & Duration of illness (years) & 6.65 & 4.02 \\
3 & Maximum amount spent on medication & 2652.5 & 1607.25 \\
4 & Maximum amount spent on Investigation & 3850.82 & 1997.5 \\
\hline
\end{tabular}

Table 3: Comparison perceived stress scale of the sample population $(N=60)$ : (post-hoc comparison)

\begin{tabular}{|c|c|c|c|c|c|c|}
\hline \multirow[b]{2}{*}{ Variable } & \multicolumn{3}{|c|}{ No $(n)$} & \multirow[b]{2}{*}{$F$} & \multirow[b]{2}{*}{$p$} & \multirow[b]{2}{*}{ Post-hoc } \\
\hline & Patients ${ }^{a}$ & Siblings ${ }^{b}$ & Control $^{c}$ & & & \\
\hline \multirow{3}{*}{ Perceived stress } & & & & & & $a>c$ \\
\hline & $20.65 \pm 4.57$ & $18.60 \pm 3.48$ & $11.30 \pm 0.80$ & 42.918 & $0.000^{* *}$ & $b>c$ \\
\hline & & & & & & $a=b$ \\
\hline
\end{tabular}

${ }^{* *} p<0.01$

siblings and normal controls. GHQ-12 was used and a person who scored less than three points in GHQ-12 was included in the study.

\section{Measures}

The measure used in the present study included sociodemographic data sheet, Perceived Stress Scale, ${ }^{4}$ and General Health Questionnaire 12 (GHQ-12)..$^{5}$ The Perceived Stress Scale 10 (PSS10 ) is a self-report instrument consisting of 10 items purported to assess "how unpredictable, uncontrollable, and over-loaded respondents find their lives." Each of the items on the PSS-10 are rated on a 5-point Likert scale, ranging from 0 (never) to 4 (very often). The PSS-10 consisted of six positively (items 1, 2, 3, 6, 9, and 10: Positive factor) and four negatively (items 4, 5, 7, and 8: Negative factor) worded items. Negatively worded items were re-coded during analysis. Total scores range from 0-40, with higher scores indicating higher levels of perceived stress.

The GHQ-12 was introduced by Goldberg and Williams in $1988 .{ }^{5}$ It is a measure of current mental health. It is a self-administered test that detects the presence of psychiatric disorders in people presenting in psychiatric care settings and nonpsychiatric clinical settings. GHQ-12 is not designed to detect symptoms of certain mental illnesses such as mental disorders, instead providing a measure of overall mental health or well-being.

\section{Statistical Analyses}

Descriptive statistics (mean and standard deviation) were used to describe sample characteristics. Inferential statistics such as the Chi-square and t-test were used to compare the perceived stress of persons with epilepsy, their siblings, and normal controls.

\section{Results}

Table 1 shows sociodemographic variable of the sample population which indicates that there is no significant difference with regard to types of family, occupation, domicile, and religion.

Table 2 indicates that the mean age of onset is 21.25 years, duration of illness is 6.65 years, rupees 2,652 is being spent for medication as well as rupees 3,850 is being spent for investigation.

Table 3 shows comparison of perceived stress patients, their siblings, and normal control which indicates patient and their sibling have more stress as compare to normal control.

\section{Discussion}

This study had been planned to assess the perceived stress of persons with epilepsy, their siblings, and normal controls. So, 20 patients diagnosed with epilepsy as per ILAE criteria, 20 siblings of patients with epilepsy, and 20 normal control individuals were 
selected through purposive sampling method. For study purpose $\mathrm{PSS}^{4}$ and GHQ-12. ${ }^{5}$ One of the few studies with a longitudinal design that used a validated stress scale assessed patients at two time points and showed that stress, measured by the PSS. ${ }^{4}$ The PSS showed adequate reliability and as predicted was correlated with life event scores, depressive and physical symptomology, utilization of health services, and social anxiety.

Our findings indicate that the onset is 21 years, these findings corroborative with the other Indian study, ${ }^{6}$ and duration of illness is 6 years the magnitude of epilepsy treatment gap in India ranges from $22 \%$ (urban middle income) to $90 \%$ (villages). ${ }^{7}$ Treatment gap is a useful indicator for accessibility and quality of epilepsy care and undoubtedly, an extremely high treatment gap would result in increased disease burden. The findings of our study described that a total of 6,502 rupees is being spent on direct cost both medication and investigation. These findings are same with previous Indian study carried out by Murthy et al. ${ }^{8}$ in Hyderabad. In our results, it is also found that patients and their siblings have significantly higher stress than control individuals. It could be explained that emotional stress, missing medication, fatigue, stigma, and long-term hospitalization are the triggering factor which, precipitate stress among patient and their siblings. Due to time constraints, sampling was relatively small and could affect generalizability of findings in the future. Other limitations of our study owe to drawbacks related to self-report measure like social desirability, memory constraints, and so on. However, we have tried to minimize these by putting post-scale introspective questions that support participant's responses. Subjects were recruited at a tertiary care hospital, and predictors of perceived stress may differ between this population and the community population of PWE. This is a cross-sectional study; we were unable to confirm the causal relationship between the variables despite looking at other evidence from the methodological analysis. Therefore, a long-term study is necessary to confirm the relationship of stress and epilepsy. However, the findings of this study have strengthened patients with what can be avoided to protect their future episodes.

\section{Conclusion}

A PWE believes that some of their seizures may be caused by more than one factor. There may be a combination of severity measures in PWEs. The findings of our study concluded that that stress and seizures are related. An individual needs to try stress reduction techniques for seizure control. We believe that these findings highlight the need for research to evaluate the role of stress and reduce stress as an alternative treatment for epilepsy; early detection, and appropriate management of psychiatric and sleep disorders in PWE can reduce stress and help to prevent further seizures.

\section{References}

1. World Health Organization. Global Campaign against Epilepsy, Programme for Neurological Diseases, Neuroscience (World Health Organization), International Bureau for Epilepsy, World Health Organization. Department of Mental Health, 2005.

2. Chadwick D, Smith, D. The misdiagnosis of epilepsy: the rate of misdiagnosis and wide treatment choices are arguments for specialist care of epilepsy. BMJ. 2002;324:495-496. DOI: 10.1136/bmj.324.7336.495

3. Novakova B, Harris PR, Ponnusamy A, et al. The role of stress as a trigger for epileptic seizures: a narrative review of evidence from human and animal studies. Epilepsia 2013;54:1866-1876. DOI: 10.1111/epi.12377

4. Cohen S, Kamarck T, Mermelstein R. A global measure of perceived stress. JHSB 1983;385-396. DOI: 10.2307/2136404

5. Goldberg DP, Williams P. User's Guide to the General Health Questionnaire. Windsor, 1988 Goldberg, DP User's Guide to the General Health Questionnaire. Windsor, 1988.

6. Kaur S, Garg R, Aggarwal S, et al. Adult onset seizures: clinical, etiological, and radiological profile. J Family Med Prim Care 2018;7: 191. DOI: $10.4103 /$ ffmpc.jfmpc_322_16

7. Meyer AC, Dua T, Ma J, Saxena S, et al. Global disparities in the epilepsy treatment gap: a systematic review. Bull. World Health Organ. 2010;88:260-266. DOI: 10.2471/BLT.09.064147

8. Murthy JMK, Rajshekar G. Economic evaluation of seizures associated with solitary cysticercus granuloma. Neurol India 2007;55:42. DOI: $10.4103 / 0028-3886.30425$ 